\title{
On Determination of Functional-Differential Pencils on Closed Sets from the Weyl-Type Function
}

\begin{abstract}
V. A. Yurko
Vjacheslav A. Yurko, https://orcid.org/0000-0002-4853-0102, Saratov State University, 83 Astrakhanskaya St., 410012 Saratov, Russia, YurkoVA@info.sgu.ru

Second-order functional-differential pencils on closed sets are considered with nonlinear dependence on the spectral parameter. Properties of their spectral characteristics are obtained and the inverse problem is studied, which consists in recovering coefficients of the pencil from the given Weyl-type function. The statement and the study of inverse spectral problems essentially depend on the structure of the closed set. We consider an important subclass of closed sets when the set is a unification of a finite number of closed intervals and isolated points. In order to solve the inverse spectral problem for this class of closed sets, we develop ideas of the method of spectral mappings. We also establish and use connections between the Weyl-type functions related to different subsets of the main closed set. Using these ideas and properties we obtain a global constructive procedure for the solution of the nonlinear inverse problem considered, and we establish the uniqueness of the solution of the inverse problem.
\end{abstract}

Keywords: functional-differential pencils, closed sets, inverse spectral problems.

Received: 10.12.2019 / Accepted: 15.02.2020 / Published: 31.08.2020

This is an open access article distributed under the terms of Creative Commons Attribution License (CC-BY 4.0)

DOI: https://doi.org/10.18500/1816-9791-2020-20-3-343-350

\section{INTRODUCTION}

We study inverse spectral problems for pencils of functional-differential operators on a closed set of the real line (in literature it is sometimes called a time scale). Such problems often appear in natural sciences and engineering [1]. Inverse spectral problems consist in constructing operators with given spectral characteristics. For differential operators on an interval inverse problems have been studied fairly completely; the main results can be found in the monographs [2,3]. Inverse spectral problems for differential pencils on an interval were considered in [4-10] and other works. Inverse problems for functional-differential operators for Sturm-Liouville operators defined on time scales were investigated in [11]. Inverse problems for pencils of functional-differential operators have not been studied yet. In Section 1. of this paper we present main notions and establish properties of spectral characteristics for pencils of functional-differential operators on closed sets, and formulate the statement of the inverse problem. In Section 2. we develop an algorithm for solution of the inverse problem of recovering the pencil from the given Weyl-type function, and prove the uniqueness of the solution.

\section{STATEMENT OF THE INVERSE PROBLEM}

Let $T$ be a closed subset of the real line; it is sometimes called a time scale. Consider the following equation on $T$ :

$$
y^{\Delta \Delta}(x)+\left(\rho^{2}+\rho p(x)+q(x)\right) y(\sigma(x))=0, \quad x \in T .
$$


Here $\rho$ is the spectral parameter, $q(x) \in C_{T}, p(x) \in C_{T}^{1}$ are complex-valued functions, $y^{\Delta}$ is the delta-derivative, $\sigma(x)=\inf \{s \in T: s>x\}$ for $x \neq \sup T, \sigma(\sup T)=\sup T$ (see [11] for notions related to equations on closed sets such as delta-derivative, $C_{T}$ and others). The statement and the study of inverse spectral problems essentially depend on the structure of the time scale $T$. In this paper we consider an important subclass of time scale, namely, the so-called $Y 1$-structure [11]. Let the set $T$ have the following structure:

$T=\bigcup_{k=1}^{N}\left[a_{k}, b_{k}\right], N \geqslant 2, b_{k-1}<a_{k} \leqslant b_{k}<a_{k+1}, a_{1}<b_{1}, a_{N}<b_{N}, a_{k}=b_{k}, k=\overline{2, N-1}$.

For $Y 1$-structure one has

$$
y^{\Delta}\left(b_{k}\right)=\frac{y\left(a_{k+1}\right)-y\left(b_{k}\right)}{a_{k+1}-b_{k}}, k=\overline{1, N-1}, \quad y^{\Delta}(x)=y^{\prime}(x), x \in\left[a_{1}, b_{1}\right] \cup\left[a_{N}, b_{N}\right] .
$$

In particular, this yields $y^{\Delta}\left(b_{1}\right)=y^{\prime}\left(b_{1}\right)$, and consequently,

$$
y\left(a_{2}\right)=y\left(b_{1}\right)+\left(a_{2}-b_{1}\right) y^{\prime}\left(b_{1}\right) .
$$

Using (1) and (2) we obtain

$$
\begin{gathered}
y^{\prime \prime}(x)+\left(\rho^{2}+\rho p(x)+q(x)\right) y(x)=0, \quad x \in\left[a_{1}, b_{1}\right] \cup\left[a_{N}, b_{N}\right], \\
y^{\Delta \Delta}\left(b_{k}\right)=\frac{1}{a_{k+1}-b_{k}}\left(\frac{y\left(a_{k+2}\right)-y\left(b_{k+1}\right)}{a_{k+2}-b_{k+1}}-\frac{y\left(a_{k+1}\right)-y\left(b_{k}\right)}{a_{k+1}-b_{k}}\right)= \\
=\left((i \rho)^{2}-\rho p\left(b_{k}\right)-q\left(b_{k}\right)\right) y\left(a_{k+1}\right), k=\overline{1, N-2}, \\
y^{\Delta \Delta}\left(b_{N-1}\right)=\frac{1}{a_{N}-b_{N-1}}\left(y^{\prime}\left(a_{N}\right)-\frac{y\left(a_{N}\right)-y\left(b_{N-1}\right)}{a_{N}-b_{N-1}}\right)= \\
=\left((i \rho)^{2}-\rho p\left(b_{N-1}\right)-q\left(b_{N-1}\right)\right) y\left(a_{N}\right) .
\end{gathered}
$$

Therefore

$$
\begin{gathered}
y\left(a_{k+2}\right)=y\left(b_{k+1}\right)+\frac{a_{k+2}-b_{k+1}}{a_{k+1}-b_{k}}\left(y\left(a_{k+1}\right)-y\left(b_{k}\right)\right)+ \\
+\left(a_{k+1}-b_{k}\right)\left(a_{k+2}-b_{k+1}\right)\left((i \rho)^{2}-\rho p\left(b_{k}\right)-q\left(b_{k}\right)\right) y\left(a_{k+1}\right), \quad k=\overline{1, N-2}, \\
y^{\prime}\left(a_{N}\right)=\frac{y\left(a_{N}\right)-y\left(b_{N-1}\right)}{a_{N}-b_{N-1}}+\left(a_{N}-b_{N-1}\right)\left((i \rho)^{2}-\rho p\left(b_{N-1}\right)-q\left(b_{N-1}\right)\right) y\left(a_{N}\right) .
\end{gathered}
$$

Denote $Q=\{p, q\}$. It follows from (3), (5), (6) that

$$
\left.\begin{array}{r}
y\left(a_{N}\right)=\alpha_{11}(\rho) y\left(b_{1}\right)+\alpha_{12}(\rho) y^{\prime}\left(b_{1}\right) \\
y^{\prime}\left(a_{N}\right)=\alpha_{21}(\rho) y\left(b_{1}\right)+\alpha_{22}(\rho) y^{\prime}\left(b_{1}\right)
\end{array}\right\}
$$

where $\alpha_{j k}(\rho)$ are polynomials with respect to $\rho$ of degree $2(N+j-3)$, and they depend on $Q\left(b_{1}\right), \ldots, Q\left(b_{N+j-3}\right)$. Moreover,

$$
\alpha_{j k}(\rho)=(i \rho)^{2(N+j-3)} \alpha_{j k}^{0}[1], \quad|\rho| \rightarrow \infty,
$$


where $\alpha_{11}^{0}=\left(a_{2}-b_{1}\right)\left(a_{N}-b_{N-1}\right) \prod_{k=2}^{N-2}\left(a_{k+1}-b_{k}\right)^{2}\left(\alpha_{11}^{0}=1\right.$ for $N=2$, and $\alpha_{11}^{0}=\left(a_{2}-b_{1}\right)\left(a_{3}-b_{2}\right)$ for $\left.N=3\right), \alpha_{12}^{0}=\left(a_{2}-b_{1}\right) \alpha_{11}^{0}, \alpha_{21}^{0}=\left(a_{N}-b_{N-1}\right) \alpha_{11}^{0}$, $\alpha_{22}^{0}=\left(a_{2}-b_{1}\right)\left(a_{N}-b_{N-1}\right) \alpha_{11}^{0}$, [1] $=1+O\left(\rho^{-1}\right)$. Without loss of generality, we assume that $a_{1}=0$.

We denote by $L_{0}$ the boundary value problem for Eq. (1) on $T$ with the boundary conditions $y(0)=y\left(b_{N}\right)=0$. Let $S(x, \rho)$ and $C(x, \rho)$ be solutions of Eq. (1) on $T$ satisfying the initial conditions $C(0, \rho)=S^{\Delta}(0, \rho)=1, S(0, \rho)=C^{\Delta}(0, \rho)=0$. Denote $\Delta_{0}(\rho):=S\left(b_{N}, \rho\right)$. The eigenvalues $\left\{\rho_{n 0}\right\}_{n \in Z}$ of the boundary value problem $L_{0}$ coincide with the zeros of the entire function $\Delta_{0}(\rho)$. The function $\Delta_{0}(\rho)$ is called the characteristic function for $L_{0}$.

Let $\Phi(x, \rho)$ be the solution of Eq. (1) on T satisfying the boundary conditions

$$
\Phi(0, \rho)=1, \quad \Phi\left(b_{N}, \rho\right)=0 .
$$

We put $M(\rho):=\Phi^{\Delta}(0, \rho)$. The function $M(\rho)$ is called the Weyl-type function. Clearly,

$$
\begin{gathered}
\Phi(x, \rho)=C(x, \rho)+M(\rho) S(x, \rho), \\
M(\rho)=-\Delta_{1}(\rho) / \Delta_{0}(\rho),
\end{gathered}
$$

where $\Delta_{1}(\rho):=C\left(b_{N}, \rho\right)$ is the characteristic function for the boundary value problem $L_{1}$ for Eq. (1) on $T$ with the boundary conditions $y^{\Delta}(0)=y\left(b_{N}\right)=0$. The zeros $\left\{\rho_{n 1}\right\}_{n \in Z}$ of $\Delta_{1}(\rho)$ coincide with the eigenvalues of $L_{1}$.

Now we need to study the asymptotical behavior of the solutions $\Phi(x, \rho)$ and $S(x, \rho)$. For this purpose we extent the functions $Q(x)$ on the whole segment $\left[a_{1}, b_{N}\right]$ such that $q(x) \in C\left[a_{1}, b_{N}\right], p(x) \in C^{1}\left[a_{1}, b_{N}\right]$ and arbitrary in the rest. Consider the equation

$$
y^{\prime \prime}(x)+\left(\rho^{2}+\rho p(x)+q(x)\right) y(x)=0, \quad x \in\left[0, b_{N}\right] .
$$

Denote

$$
\begin{gathered}
E(x)=\frac{1}{2} \int_{0}^{x} p(t) d t, \quad \Pi_{ \pm}=\{\rho: \pm \operatorname{Im} \rho>0\}, \\
\Pi_{\delta}^{+}=\{\rho: \arg \rho \in[\delta, \pi-\delta]\}, \quad \Pi_{\delta}^{-}=\{\rho: \arg \rho \in[\pi+\delta, 2 \pi-\delta]\} .
\end{gathered}
$$

It is known (see, for example, [2]) that there exist fundamental systems of solutions of Eq. (12) $\left\{Y_{1}^{ \pm}(x, \rho), Y_{2}^{ \pm}(x, \rho)\right\}, x \in\left[0, b_{N}\right], \rho \in \overline{\Pi_{ \pm}},|\rho|>\rho_{0}$, having the following asymptotical behavior for each fixed $x \in\left[0, b_{N}\right], \nu=0,1$ as $|\rho| \rightarrow \infty$ :

$$
\begin{gathered}
\frac{d^{\nu}}{d x^{\nu}} Y_{1}^{ \pm}(x, \rho)=(i \rho)^{\nu} \exp (i(\rho x+E(x)))[1] \\
\frac{d^{\nu}}{d x^{\nu}} Y_{2}^{ \pm}(x, \rho)=(-i \rho)^{\nu} \exp (-i(\rho x+E(x)))[1]
\end{gathered}
$$

Taking (7) into account we conclude that the function $\Phi(x, \rho)$ is the solution of Eq. (4) satisfying the boundary conditions (9) and the jump conditions

$$
\left.\begin{array}{c}
\Phi\left(a_{N}, \rho\right)=\alpha_{11}(\rho) \Phi\left(b_{1}, \rho\right)+\alpha_{12}(\rho) \Phi^{\prime}\left(b_{1}, \rho\right), \\
\Phi^{\prime}\left(a_{N}, \rho\right)=\alpha_{21}(\rho) \Phi\left(b_{1}, \rho\right)+\alpha_{22}(\rho) \Phi^{\prime}\left(b_{1}, \rho\right) .
\end{array}\right\}
$$


Using the fundamental system of solutions $\left\{Y_{1}^{+}(x, \rho), Y_{2}^{+}(x, \rho)\right\}$, for $\rho \in \overline{\Pi_{+}}$one has:

$$
\left.\begin{array}{c}
\Phi(x, \rho)=A_{1}(\rho) Y_{1}^{+}(x, \rho)+A_{2}(\rho) Y_{2}^{+}(x, \rho), x \in\left[0, b_{1}\right], \\
\Phi(x, \rho)=B_{1}(\rho) Y_{1}^{+}(x, \rho)+B_{2}(\rho) Y_{2}^{+}(x, \rho), x \in\left[a_{N}, b_{N}\right] .
\end{array}\right\}
$$

Substituting (15) into (9) and (14) and using (13), we obtain the following linear algebraic system with respect to $A_{k}(\rho)$ and $B_{k}(\rho)$ :

$$
\begin{gathered}
A_{1}(\rho)[1]+A_{2}(\rho)[1]=1, \\
B_{1}(\rho) \exp \left(i\left(\rho b_{N}+E\left(b_{N}\right)\right)\right)[1]+B_{2}(\rho) \exp \left(-i\left(\rho b_{N}+E\left(b_{N}\right)\right)\right)[1]=0, \\
B_{1}(\rho) \exp \left(i\left(\rho a_{N}+E\left(a_{N}\right)\right)\right)[1]+B_{2}(\rho) \exp \left(-i\left(\rho a_{N}+E\left(a_{N}\right)\right)\right)[1]= \\
=\alpha_{11}(\rho)\left(A_{1}(\rho) \exp \left(i\left(\rho b_{1}+E\left(b_{1}\right)\right)\right)[1]+A_{2}(\rho) \exp \left(-i\left(\rho b_{1}+E\left(b_{1}\right)\right)\right)[1]\right)+ \\
+\alpha_{12}(\rho)\left(A_{1}(\rho)(i \rho) \exp \left(i\left(\rho b_{1}+E\left(b_{1}\right)\right)\right)[1]+A_{2}(\rho)(-i \rho) \exp \left(-i\left(\rho b_{1}+E\left(b_{1}\right)\right)\right)[1]\right), \\
B_{1}(\rho)(i \rho) \exp \left(i\left(\rho a_{N}+E\left(a_{N}\right)\right)\right)[1]+B_{2}(\rho)(-i \rho) \exp \left(-i\left(\rho a_{N}+E\left(a_{N}\right)\right)\right)[1]= \\
=\alpha_{21}(\rho)\left(A_{1}(\rho) \exp \left(i\left(\rho b_{1}+E\left(b_{1}\right)\right)\right)[1]+A_{2}(\rho) \exp \left(-i\left(\rho b_{1}+E\left(b_{1}\right)\right)\right)[1]\right)+ \\
+\alpha_{22}(\rho)\left(A_{1}(\rho)(i \rho) \exp \left(i\left(\rho b_{1}+E\left(b_{1}\right)\right)\right)[1]+A_{2}(\rho)(-i \rho) \exp \left(-i\left(\rho b_{1}+E\left(b_{1}\right)\right)\right)[1]\right) .
\end{gathered}
$$

Taking (8) into account we deduce that the determinant $D(\rho)$ of this system has the form

$$
\begin{gathered}
D(\rho)=(i \rho) \alpha_{22}(\rho)\left(\exp \left(i \rho\left(b_{N}-a_{N}\right)\right) \exp \left(i\left(E\left(b_{N}\right)-E\left(a_{N}\right)\right)\right)[1]-\right. \\
\left.-\exp \left(-i \rho\left(b_{N}-a_{N}\right)\right) \exp \left(-i\left(E\left(b_{N}\right)-E\left(a_{N}\right)\right)\right)[1]\right) \times \\
\times\left(\exp \left(i\left(\rho b_{1}+E\left(b_{1}\right)\right)\right)[1]-\exp \left(-i\left(\rho b_{1}+E\left(b_{1}\right)\right)\right)[1]\right), \quad|\rho| \rightarrow \infty, \rho \in \overline{\Pi_{+}} .
\end{gathered}
$$

Solving this algebraic system by Cramer's rule and using (8) and (16), for $|\rho| \rightarrow \infty, \rho \in \Pi_{\delta}^{+}$we get:

$$
\begin{gathered}
A_{1}(\rho)=[1], \quad A_{2}(\rho)=\exp \left(2 i \rho b_{1}\right)[1], \\
B_{1}(\rho)=\exp \left(-i \rho\left(a_{N}-b_{1}\right)\right) O\left(\rho^{2 N-4}\right)[1], \\
B_{2}(\rho)=\exp \left(-i \rho\left(a_{N}-b_{1}\right)\right) \exp \left(2 i \rho b_{N}\right) O\left(\rho^{2 N-4}\right)[1] .
\end{gathered}
$$

In particular for each fixed $x \in\left(0, b_{1}\right)$ this yields:

$$
\Phi^{(\nu)}(x, \rho)=(i \rho)^{\nu} \exp (i(\rho x+E(x)))[1], \quad \nu=0,1,|\rho| \rightarrow \infty, \rho \in \Pi_{\delta}^{+} .
$$

Repeating these calculations for $\rho \in \bar{\Pi}_{-}$, for each fixed $x \in\left(0, b_{1}\right)$ we get:

$$
\Phi^{(\nu)}(x, \rho)=(-i \rho)^{\nu} \exp (-i(\rho x+E(x)))[1], \quad \nu=0,1,|\rho| \rightarrow \infty, \rho \in \Pi_{\delta}^{-} .
$$

Similarly, we obtain

$$
\begin{array}{r}
S^{(\nu)}(x, \rho)=-\frac{(-i \rho)^{\nu}}{2 i \rho} \exp (-i(\rho x+E(x)))[1], \quad \nu=0,1,|\rho| \rightarrow \infty, \rho \in \Pi_{\delta}^{+}, \\
S^{(\nu)}(x, \rho)=\frac{(i \rho)^{\nu}}{2 i \rho} \exp (i(\rho x+E(x)))[1], \quad \nu=0,1,|\rho| \rightarrow \infty, \rho \in \Pi_{\delta}^{-},
\end{array}
$$

for each fixed $x \in\left(0, b_{1}\right)$. 


\section{SOLUTION OF THE INVERSE PROBLEM}

Let the numbers $Q\left(b_{2}\right), \ldots, Q\left(b_{N-1}\right)$ be known a priori. The inverse problem is formulated as follows: given $M(\rho)$, construct $Q=\{p, q\}$ on $T$.

In order to solve this inverse problem we will use the ideas of the method of spectral mappings [3]. Let us prove the uniqueness theorem for the solution of the inverse problem. For this purpose together with $L_{0}$ we consider a boundary value problem $\tilde{L}_{0}$ of the same form but with another potentials $\tilde{Q}$. We agree that if a certain symbol $\theta$ denotes an object related to $L_{0}$, then $\tilde{\theta}$ will denote an analogous object related to $\tilde{L}_{0}$.

Theorem 1. If $M(\rho)=\tilde{M}(\rho)$, then $Q=\tilde{Q}$ on $T$. Thus, the specification of the Weyl-type function $M(\rho)$ uniquely determines the potential $Q$.

Proof. For $x \in\left(0, b_{1}\right)$, we define the matrix $P(x, \rho)=\left[P_{j k}(x, \rho)\right]_{j, k=1,2}$ by the formula

$$
P(x, \rho)\left[\begin{array}{cc}
\tilde{\Phi}(x, \rho) & \tilde{S}(x, \rho) \\
\tilde{\Phi}^{\prime}(x, \rho) & \tilde{S}^{\prime}(x, \rho)
\end{array}\right]=\left[\begin{array}{cc}
\Phi(x, \rho) & S(x, \rho) \\
\Phi^{\prime}(x, \rho) & S^{\prime}(x, \rho)
\end{array}\right] .
$$

Since $\Phi(x, \rho) S^{\prime}(x, \rho)-\Phi^{\prime}(x, \rho) S(x, \rho) \equiv 1$, it follows from (21) that

$$
\left.\begin{array}{c}
P_{11}(x, \rho)=\Phi(x, \rho) \tilde{S}^{\prime}(x, \rho)-S(x, \rho) \tilde{\Phi}^{\prime}(x, \rho), \\
P_{12}(x, \rho)=S(x, \rho) \tilde{\Phi}(x, \rho)-\Phi(x, \rho) \tilde{S}(x, \rho),
\end{array}\right\}
$$

It follows from (17)-(20) that for each fixed $x \in\left(0, b_{1}\right)$,

$$
P_{11}(x, \rho)=\Omega(x)+O\left(\rho^{-1}\right), P_{12}(x, \rho)=O\left(\rho^{-1}\right),|\rho| \rightarrow \infty, \rho \in \Pi_{\delta}^{ \pm},
$$

where $\Omega(x)=\cos (E(x)-\tilde{E}(x))$. On the other hand, using (10) and the assumption of the theorem, we get

$$
\begin{gathered}
P_{11}(x, \rho)=C(x, \rho) \tilde{S}^{\prime}(x, \rho)-\tilde{C}^{\prime}(x, \rho) S(x, \rho), \\
P_{12}(x, \rho)=\tilde{C}(x, \rho) S(x, \rho)-C(x, \rho) \tilde{S}(x, \rho),
\end{gathered}
$$

and consequently, for each fixed $x \in\left(0, b_{1}\right)$, the functions $P_{11}(x, \rho)$ and $P_{12}(x, \rho)$ are entire in $\rho$ of exponential type. Together with (24) this yields

$$
P_{11}(x, \rho) \equiv \Omega(x), \quad P_{12}(x, \rho) \equiv 0 .
$$

It follows from (23) that

$$
\Phi(x, \rho)=\Omega(x) \tilde{\Phi}(x, \rho), \quad S(x, \rho)=\Omega(x) \tilde{S}(x, \rho), \quad x \in\left(0, b_{1}\right),
$$

for all complex $\rho$. Therefore,

$$
\frac{\Phi(x, \rho)}{\tilde{\Phi}(x, \rho)}=\frac{S(x, \rho)}{\tilde{S}(x, \rho)}=\Omega(x), \quad x \in\left(0, b_{1}\right) .
$$


Taking (17)-(20) into account for $|\rho| \rightarrow \infty$ we infer that:

$$
\begin{aligned}
& \frac{\Phi(x, \rho)}{\tilde{\Phi}(x, \rho)}=\exp (i(E(x)-\tilde{E}(x))), \frac{S(x, \rho)}{\tilde{S}(x, \rho)}=\exp (-i(E(x)-\tilde{E}(x))), \rho \in \Pi_{\delta}^{+}, \\
& \frac{\Phi(x, \rho)}{\tilde{\Phi}(x, \rho)}=\exp (-i(E(x)-\tilde{E}(x))), \frac{S(x, \rho)}{\tilde{S}(x, \rho)}=\exp (i(E(x)-\tilde{E}(x))), \rho \in \Pi_{\delta}^{-} .
\end{aligned}
$$

Together with $(22)$ this yields $\exp (2 i(E(x)-\tilde{E}(x))) \equiv 1$. Since $E(0)-\tilde{E}(0)=0$, it follows that $E(x)-\tilde{E}(x) \equiv 0$. Hence $\Omega(x) \equiv 1$ for $x \in\left[0, b_{1}\right]$. Using (25) we calculate $P_{11}(x, \rho)=1$, and $p(x)=\tilde{p}(x)$ for all $x \in\left[0, b_{1}\right]$. It follows from (26) that

$$
\Phi(x, \rho)=\tilde{\Phi}(x, \rho), \quad S(x, \rho)=\tilde{S}(x, \rho),
$$

for all $x \in\left[0, b_{1}\right]$, and consequently, $Q(x)=\tilde{Q}(x)$ for all $x \in\left[0, b_{1}\right]$. Using the method of spectral mappings [3] we also obtain an algorithm for constructing the potentials $p(x)$ and $q(x)$ for $x \in\left[0, b_{1}\right]$.

Denote

$$
\Phi_{1}(x, \rho):=\frac{\Phi(x, \rho)}{\Phi\left(a_{N}, \rho\right)}, \quad M_{1}(\rho):=\Phi_{1}^{\prime}\left(a_{N}, \rho\right)=\frac{\Phi^{\prime}\left(a_{N}, \rho\right)}{\Phi\left(a_{N}, \rho\right)} .
$$

Since $\Phi_{1}\left(a_{N}, \rho\right)=1, \Phi_{1}\left(b_{N}, \rho\right)=0$, it follows that the function $M_{1}(\rho)$ is the Weyl-type function for Eq. (4) on the segment $\left[a_{N}, b_{N}\right]$. Taking (14) and (27) into account we infer $M_{1}(\rho)=\tilde{M}_{1}(\rho)$. The specification of the Weyl-type function $M_{1}(\rho)$ uniquely determines the potentials $p(x)$ and $q(x)$ for $x \in\left[a_{N}, b_{N}\right]$. This means that Theorem 1 is proved, and the solution of the inverse problem can be found by the following algorithm.

Algorithm 1. Let the function $M(\rho)$ be given.

1. Construct $p(x), q(x)$ and $\Phi(x, \rho)$ for $x \in\left[a_{1}, b_{1}\right]$ using the method of spectral mappings.

2. Find $\Phi\left(a_{N}, \rho\right)$ and $\Phi^{\prime}\left(a_{N}, \rho\right)$ via (14).

3. Calculate $M_{1}(\rho)$ by $(28)$.

4. Construct $p(x), q(x)$ and $\Phi(x, \rho)$ for $x \in\left[a_{N}, b_{N}\right]$ by the method of spectral mappings.

We note that the inverse problem of recovering the potentials $p(x)$ and $q(x)$ from the given two spectra $\left\{\rho_{n j}\right\}_{n \geqslant 1}, j=0,1$, can be reduced to the solution of the inverse problem from the Weyl-type function. Indeed, using Hadamard's factorization theorem one can uniquely reconstruct the characteristic functions $\Delta_{j}(\rho), j=0,1$, and then calculate $M(\rho)$ by (11).

Acknowledgements: This investigation was supported in part by the Russian Foundation for Basic Research (project No. 19-01-00102).

\section{References}

1. Bohner M., Peterson A. Dynamic Equations on Time Scales. Boston, MA, Birkhäuser, 2001. 358 p. DOI: https://doi.org/10.1007/978-1-4612-0201-1

2. Freiling G., Yurko V. A. Inverse Sturm-Liouville Problems and Their Applications. New York, NOVA Science Publ. Inc., 2001. 305 p.

3. Yurko V. A. Method of Spectral Mappings in the Inverse Problem Theory. Utrecht, VSP, 2002. 316 p. Inverse and Ill-posed Problems Series. 
4. Gasymov M. G., Gusejnov G. S. Determination of diffusion operators from the spectral data. DAN Azer. SSR, 1981, vol. 37, no. 2, pp. 19-23.

5. Yurko V. A. Boundary value problems with a parameter in the boundary conditions. Soviet J. Contemporary Math. Anal., 1984, vol. 19, no. 5, pp. 62-73.

6. Yurko V. A. An inverse problem for pencils of differential operators. Sb. Math., 2000, vol. 191, iss. 10, pp. 1561-1586. DOI: http://dx.doi.org/10.1070/ SM2000v191n10ABEH 000520

7. Nabiev I. M. Inverse spectral problem for the diffusion operator on an interval. Mat. Fiz. Anal. Geom., 2004, vol. 11, no. 3, pp. 302-313.

8. Guseinov I., Nabiev I. The inverse spectral problem for pencils of differential operators. Sb. Math., 2007, vol. 198, iss. 11, pp. 1579-1598. DOI: http://dx.doi.org/10.1070/ SM2007v198n11ABEH003897

9. Buterin S. A., Yurko V. A. Inverse problems for second-order differential pencils with Dirichlet boundary conditions. J. Inverse Ill-Posed Probl., 2012, vol. 20, iss. 5-6, pp. 855881. DOI: https://doi.org/10.1515/jip-2012-0062

10. Yurko V. A. Inverse problems for non-selfadjoint quasi-periodic differential pencils. Anal. Math. Phys., 2012, vol. 2, no. 3, pp. 215-230. DOI: https://doi.org/10.1007/s13324-0120030-9

11. Yurko V. A. Inverse problems for Sturm-Liouville differential operators on closed sets. Tamkang Journal of Mathematics, 2019, vol. 50, no. 3, pp. 199-206. DOI: https://doi.org/10.5556/j.tkjm.50.2019.3343

Cite this article as:

Yurko V. A. On Determination of Functional-Differential Pencils on Closed Sets from the WeylType Function. Izv. Saratov Univ. (N. S.), Ser. Math. Mech. Inform., 2020, vol. 20, iss. 3, pp. 343-350. DOI: https://doi.org/10.18500/1816-9791-2020-20-3-343-350

УДК 517.984

\section{Об определении функционально-диффреренциальных пучков на замкнутых множествах по функции типа Вейля}

\section{B. А. Юрко}

Юрко Вячеслав Анатольевич, доктор фризико-математических наук, заведующий кафедрой математической фризики и вычислительной математики, Саратовский национальный исследовательский государственный университет имени Н. Г. Чернышевского, Россия, 410012, г. Саратов, ул. Астраханская, д. 83, YurkoVA@info.sgu.ru

Рассматриваются функционально-дифрференциальные пучки на замкнутых множествах вещественной оси с нелинейной зависимостью от спектрального параметра. Получены свойства их спектральных характеристик и исследуется обратная задача, которая состоит в восстановлении коэффрициентов пучка по заданной фрункции типа Вейля. Постановка и исследование обратных задач существенно зависят от структуры замкнутого множества. Рассматривается важный класс замкнутых множеств, когда множество является объединением конечного набора отрезков и изолированных точек. Чтобы решить обратную задачу для этого класса замкнутых множеств, дается развитие идей метода спектральных отображений. Также установлены и используются связи между фуннциями типа Вейля, относящиеся к разным подмножествам основного замкнутого множества. С помощью этих идей и свойств получена глобальная конструктивная процедура решения рассматриваемой нелинейной обратной задачи, а также установлена единственность решения этой обратной задачи. 
Ключевые слова: фрункционально-дифрференциальные пучки, замкнутые множества, обратная спектральная задача.

Поступила в редакцию: 10.12.2019 / Принята: 15.02.2020 / Опубликована: 31.08.2020

Статья опубликована на условиях лицензии Creative Commons Attribution License (CC-BY 4.0)

Благодарности. Исследование выполнено при частичной финансовой поддержке РФФИ (проект № 19-01-00102).

\section{Образец для цитирования:}

Yurko $V$. A. On Determination of Functional-Differential Pencils on Closed Sets from the Weyl-Type Function [Юрко B. А. Об определении функционально-дифференциальных пучков на замкнутых множествах по функции типа Вейля] // Изв. Сарат. ун-та. Нов. сер. Сер. Математика. Механика. Информатика. 2020. Т. 20, вып. 3. С. 343-350. DOI: https://doi.org/10.18500/1816-9791-2020-20-3-343-350 